\title{
A REAL-TIME NON-LINEAR VEHICLE PREVIEW MODEL
}

\author{
B.V. Linström, P.S. Els ${ }^{\dagger}$ T.R. Botha ${ }^{\dagger}$ \\ ${ }^{\dagger}$ Department of Mechanical and Aeronautical Engineering, \\ University of Pretoria, Pretoria 0002, South Africa.
}

\section{Bernard.Linstrom@toyota-europe.com, Schalk.Els@up.ac.za, Theunis.Botha@up.ac.za}

Bernard Villiers Linström received his M.Eng in Mechanical Engineering at the University of Pretoria, South Africa, in 2015. He is currently working as a Chassis Engineer at the Toyota Motor Europe Research and Development Centre. His research interests are vehicle dynamics, model based design and suspension control.

Pieter Schalk Els worked in industry, developing and testing military wheeled vehicles for 5 years. He was actively involved in many of the new technology projects developed by the company as well as applied research. Highlights include semiactive dampers for heavy vehicles (6 ton axle loads) as well as the world's first semi-active hydraulic rotary damper for a heavy vehicle (with Horstman Defence). In 1999 he joined the Department of Mechanical and Aeronautical Engineering at the University of Pretoria as a permanent staff member and obtained a PhD from the University of Pretoria in 2006. His current research effort is focussed on the use of semi-active dampers, combined with semi-active springs and ride height adjustment to improve ride comfort, handling, rollover propensity and life of off-road and heavy vehicles.

Theunis Richard Botha received his $\mathrm{PhD}$ in Mechanical Engineering from the University of Pretoria, South Africa, in 2015. He is a full time lecturer at the University of Pretoria, South Africa. His research interest are dynamics, integrated vehicle safety systems and autonomous vehicle control, mechatronics and parameter estimation and digital image correlation

\section{Abstract}

Motor vehicle accident statistics indicate that fatalities due to rollover of Sport Utility

Vehicles (SUVs) are of high international concern. These vehicles are designed to be used on both smooth roads and rough off-road terrains. As a result of the typically softer suspension, as well higher centre of gravity (CG), compared to passenger vehicles, SUVs are more prone to rollover.

Researchers have developed control strategies for prevention or mitigation of rollover based on the current state of the vehicle. Most of these strategies have the same drawback being a delay in switching. Further delays are introduced by the controllers and actuators used to 
control vehicles dynamics (actuators, valves etc.). This paper proposes a real-time non-linear vehicle preview model capable of accurately predicting vehicle states a finite time step ahead based on the current state of the vehicle. The VPM is developed and experimentally validated on a Land Rover Defender 110 SUV fitted with a controllable hydro-pneumatic suspension system. Results indicate that several important vehicle states, including roll angle and lateral acceleration, can be accurately predicted up to more than $0.25 \mathrm{~s}$ into the future.

Vehicle dynamics controllers can use the previewed states instead of the measured states to eliminate delays and make the strategies proactive instead of reactive.

\section{INTRODUCTION}

Sport Utility Vehicles have grown in popularity over the past years and even though these vehicles are predominantly designed for off-road conditions, most SUVs never get off the beaten track. In the U.S.A. 39\% of people feel more powerful when driving a SUV and 50\% do not consider that loading the vehicle increases the risk of rollover (Governer's Office of Consumer Affairs, 2013). SUVs have a higher ride height and softer suspension than most passenger vehicles making them ideal for off-road conditions. The combination of a higher ride height and softer suspension make SUVs more prone to rollover than other types of vehicle.

In the U.S.A. $33 \%$ of vehicle accident fatalities are due to vehicles that roll, while vehicle rollover only accounts for $2.3 \%$ of all types of accidents (Strashny, 2007). In South Africa in $2009,24 \%$ of the total number of accidents were rollover related and these contributed $25 \%$ to the total number of fatalities (second to pedestrian related accidents at 28\%). Rollover accidents had a severity rate of 1.32 fatalities per accident (Road Traffic Management 
Corporation, 2009). In Australia, rollover accidents make up 10\% of the total number of accidents, but $22 \%$ of all fatal accidents are due to rollover (Australian College of Road Safety, 2009). From the statistical databases it can be concluded that vehicle rollover is a serious type of accident and that many SUV occupants lose their lives due to rollover.

These disturbing statistics motivate researchers to find methods of improving the safety and handling of SUVs which in turn would decrease the number of rollover accidents these vehicles are involved in. The proposed methods include amongst others the use of active antiroll bars (Cronje and Els, 2006), slow-active (van der Westhuizen and Els, 2013), semi-active (Els, 2006) and active suspension (Rahman and Rideout, 2012). The control strategies of most of these methods are based on the current vehicle state, giving them the same downfall which is a delay in switching. In certain cases the point at which the control strategy detects the onset of loss of vehicle control the control action may be too late to prevent it.

A control system implemented on a vehicle goes through different steps before the output has any effect on the dynamics of the vehicle. The control system (Figure 1) can be anything from a human driver to a driver assist system or fully autonomous control implemented on the vehicle. The inputs need to be processed to make the required decision and send out the necessary control signals to the actuators. All of this contributes to the total delay of the system. The output signal is sent to the actuator on the vehicle which creates a further delay that depends on the actuator response time. In many of these steps sensor data is additionally filtered to decrease noise, causing additional delays. The final delay is due to the amount of time required for the vehicle to respond to these changes.

To compensate for this delay some form of preview can be highly beneficial. Preview models allow the vehicle to predict the future and make control decisions using the predicted states. Some vehicle preview systems used and developed in the past include wheelbase preview 
(Feng et al., 2009), convoy preview (Rahman and Rideout, 2012) and steering preview based on a Global Positioning System (Yim, 2011). Research has also been done on rollover threat, rollover warning and time to rollover (Chen and Peng, 1999), (Licea and Cervantes, 2012) and (Sanchez et al. 2004).

The aim of this paper is to develop and validate a real-time non-linear vehicle preview model (VPM) that can predict important vehicle states accurately into the future. The VPM outputs can then be used to improve existing control strategies by decreasing or eliminating the switching delay.

\section{VEHICLE PREVIEW MODEL}

This section is aimed at developing and validating a non-linear VPM capable of predicting the vehicle state at some time in the future based on the current vehicle state. Using these predicted vehicle states, the severity of a future manoeuvre, which may result in loss of control or stability of the vehicle (such as vehicle rollover), can be detected and the necessary precautionary measures taken in advance to improve the safety of the occupants in the vehicle. The preview information can also eliminate or reduce the time delay present in many vehicle control systems.

In this paper the VPM was developed specifically for fast and accurate lateral acceleration and roll angle predictions, meaning that the preview accuracy of some of the vehicle states were sacrificed to achieve the required computational efficiency to enable real-time implementation. If the accuracy of other predicted states is more important, the assumptions made can easily be adapted. 


\subsection{Vehicle dynamics}

To achieve computational efficiency for real-time implementation, a simplified vehicle model is required. The proposed model considers the lateral, yaw and roll dynamics of the vehicle body making it a 3-DOF model.

The only forces modelled acting on the vehicle are the vertical and lateral tyre forces as well as gravity. The tyres generate the required lateral forces $\left(F_{l f}, F_{r f}, F_{l r}, F_{r r}\right)$ that enable the driver to control the vehicle. Considering Figure 2 the lateral and yaw equations of motions of the 3-DOF are:

$$
\begin{gathered}
\sum F_{y}=m \ddot{y} \\
m \ddot{y} \approx m V(\dot{\beta}+r)=F_{l f}+F_{r f}+F_{l r}+F_{r r} \\
\dot{\beta}=\frac{F_{l f}+F_{r f}+F_{l r}+F_{r r}}{m V}-r
\end{gathered}
$$

The lateral equations of motion in equations (1)-(3) are written such that the rate of change of the vehicle side-slip angle is the subject of the equation. This is in order to directly solve for the side-slip angle of the vehicle in the model, simplifying the solution. It should be noted that the model does not include aerodynamic forces due to the assumption that the vehicle maintains a constant longitudinal speed by means of the engine. The force required by the 
vehicle to overcome aerodynamic drag at the speeds tested would have a small effect on the tyre characteristics which is assumed to be negligible. The roll degree of freedom of the model is modelled as in Figure 3. From this figure the roll degree of freedom equation is written as:

$$
\begin{gathered}
\sum M_{x}=I_{x} \ddot{\varphi} \\
\ddot{\varphi}=\frac{\left(F_{S l}-F_{S r}\right) \frac{t_{s}}{2}+h_{r}\left(m_{b} \ddot{y}\right)}{I_{x}} \\
\dot{\varphi}=\frac{d \varphi}{d t}
\end{gathered}
$$

with the second order roll rate broken into two single differential equations, (7) and (8), in order to obtain the vehicle roll rate and roll angle. Both these states are needed in the suspension model as described in section 2.3. All vehicle parameters such as mass, distances and mass moments of inertia where determined experimentally.

\subsection{Tyre forces}

The lateral tyre force is primarily dependant on the tyre side-slip angle and tyre vertical load. The tyre forces are modelled using the Magic Formula (MF) '89 model developed by Pajecka (Pacejka et al., 1989). The MF is an empirical fit of the tyre lateral force as a function of the tyre slip angle and vertical tyre force. The MF for lateral tyre force makes use of a sin and an arctan function to represent the general shape of the lateral force, slip angle and vertical force relationship. The formula consists of 14 coefficients which are optimised to fit experimentally obtained data and from which the lateral force at any tyre operating condition can be determined. The MF is often used in simulations, especially handling, due to its simplistic nature, quick solving time and good accuracy. The MF for the VPM was generated 
from experimentally obtained data of the tyre. Using the MF the lateral tyre force is determined from the side-slip angle and vertical load at each tyre.

The side-slip angle of the front wheels can be altered by means of steering the front wheels and therefore allows the motion of the vehicle to be controlled. The side slip angles at all wheels are also a function of longitudinal velocity, vehicle slip angle, yaw rate as well as the geometry of the vehicle. The side-slip angle at each tyre is calculated using equations (9) to (12) as defined by Abe (Abe, 2009):

$$
\begin{gathered}
\beta_{l f} \approx \frac{V \beta+l_{f} r}{V-d_{f} r / 2}-\delta \\
\beta_{r f} \approx \frac{V \beta+l_{f} r}{V+d_{f} r / 2}-\delta \\
\beta_{l r} \approx \frac{V \beta-l_{r} r}{V-d_{r} r / 2} \\
\beta_{r r} \approx \frac{V \beta-l_{r} r}{V+d_{r} r / 2}
\end{gathered}
$$

The vertical forces on the tyres are obtained from the suspension forces as well as the unsprung mass.

\subsection{Suspension forces}

The Land Rover Defender 110 test vehicle is equipped with a semi-active hydro-pneumatic suspension system. The governing equations modelling the suspension strut are quite 
complex and very slow to solve for. In order to simplify and speed up the model, the hydropneumatic spring is modelled using the ideal gas law while the damper forces are fitted using multiple second degree polynomials describing different sections of the force characteristics. The damper force and polynomial fits are shown in Figure 4. Mass and inertia properties of the vehicle were experimentally determined (Uys et al., 2006). The model also contains bumps stops and is described in detail in (Thoresson, 2007). The hydro-pneumatic suspension system contains seals which generate friction in the strut. This friction is rather for a suspension syste. The friction is however neglected in the model due to the increased stiffness it creates in the roll degree of freedom requiring a much smaller step size in order to solve. Therefore, a slight discrepancy in the strut displacement is expected and therefore the vehicle body roll as well. The suspension system is semi-active and can switch between a stiff or soft spring and low and high damping. In most cases the suspension is required to be fully stiff using high damping and stiff spring or completely soft using low damping and a soft spring. The VPM is tested for both suspension settings and the selected suspension setting is provided as input to the model.

The front and rear suspension of the vehicle consists of a solid axle connected to the chassis via two leading and trailing arms, respectively. It is assumed that the front and rear roll angles are of equal magnitudes. Figure 5 shows experimentally measured front and rear roll angles of the vehicle during a ISO Double Lane Change (DLC) on a smooth road which confirms this assumption. The assumption is also made that the left and right strut displacement and velocities are identical in magnitude but in opposite directions, i.e. the vehicle body rolls around the center of mass and the center of mass height remains constant. Figure 6 shows the measured left and right suspension displacements and indicate that they are not symmetric. This assumption, while not valid as the jacking up of the vehicle body is neglected, simplifies the model significantly and will be shown to not adversely affect the vehicle body roll angle 
prediction. Figure 7 shows the estimated suspension displacements during a DLC with the suspension settings on soft spring and damper, the figure indicates that the model error on peak sis up to $40 \%$. It should however be noted that there is an offset in the data due to the friction in the model. It will however b shown that the estimated roll angle can be estimated accurately. Inclusion of the friction in the strut should further improve the roll angle estimation

The strut velocities and displacements are therefore determined as:

$$
\begin{gathered}
z_{S l}=-\frac{t_{s}}{2} \varphi \\
z_{S r}=\frac{t_{s}}{2} \varphi \\
\dot{z}_{S l}=-\frac{t_{s}}{2} \dot{\varphi} \\
\dot{z}_{S r}=\frac{t_{s}}{2} \dot{\varphi}
\end{gathered}
$$


These velocities and displacements are used to calculate the suspension force from which the vertical force on each tyre can be determined by adding the weight of the unsprung mass. The tyre vertical force and tyre side slip angle is used in a Magic Tyre Formula to determine the lateral tyre force which in turn is used in the differential equations of the vehicle model.

The VPM makes the following additional assumptions:

- No aerodynamic or rolling resistance forces are considered.

- Only the lateral load transfer is considered.

- The CG of the vehicle remains fixed with respect to the vehicle and loading the vehicle with passengers or luggage has a negligible effect on the position of the CG.

- Tyre deflection has no effect on the roll angle of the vehicle.

- The roll angle at the front axle equals the roll angle at the rear axle.

- The steer rate remains constant for the entire preview time period.

It is further assumed that the vehicle parameters remain constant. This assumption is not always valid as the vehicle parameters may change due to loading of the vehicle. The position of the CG, the mass and mass moment of inertia may therefore change. Additionally the tyre characteristics may change due to degradation of the tyre or when new tyres are fitted. The system would therefore benefit from a model update procedure or parameter estimation which can update the vehicle parameters using on board sensors, such as accelerometers, gyroscopes, ride height sensors, etc. 


\subsection{Preview Prediction}

The equations of motion presented in (3), (5), (7) and (8) are solved using a fixed step $4^{\text {th }}$ order ordinary differential equation solver. The roll degree of freedom is split into two single order differential equations, equations (7) and (8), to solve for the roll velocity and roll angle. This creates four states which are solved namely the slip angle, yaw rate, roll rate and roll angle. A block diagram of the inputs and outputs of the VPM are provided in Figure 8 . The lateral acceleration can be determined from either the generated lateral forces or the yaw rate, vehicle speed and slip rate as per equation (2). The inputs to the model are the initial conditions of each state. The other inputs include the vehicle speed, steer angle and steer rate.

While the slip angle can be measured using a speed over ground optical sensor (Correvit SHR), this sensor is considered expensive and can therefore not be employed in commercial vehicles. The sensor was used during testing only as a means for comparison and it is not feasible to use it in the VPM. Since the slip angle is not measured directly, two methods are proposed to obtain its initial condition. The first is to simply assume that the slip-angle initial condition is always zero. This reduces the accuracy obtained from the VPM but will be shown to be fairly insignificant. An alternative method is to use the slip angle rate from the first time step in the VPM to integrate for the slip angle over time and therefore generate a slip angle measurement. This method should have better accuracy compared to the zero slip method. The roll and yaw rates are obtained directly from inexpensive solid state gyroscopes and the roll angle is obtained from simply integrating the roll rate. 
The steering rate $(\dot{\delta})$ was calculated from the measured steering angle $(\delta)$ using the backwards differencing method of two data points which are spaced 50ms apart in equation (17). This was done to reduce the noise on the steering rate signal as the VPM was found to be very sensitive to noise in the steer rate. This calculation does however introduce a short phase lag which slightly reduces the preview time. It is assumed that the steering rate is constant for the duration of the simulation. This assumption is normally only valid for short periods and will show to deteriorate the results at longer preview times.

$$
\dot{\delta}(i)=\frac{\delta_{t}-\delta_{t-50 m s}}{50 m s}
$$

The integration of the slip rate and roll rate would eventually result in drift. The drift can be removed by zeroing the values when steady state non cornering condition is detected by means of the gyroscopes and accelerometers. Therefore, drift would only be present during the cornering event itself, since we are mostly interested in short events the drift should be minimal but is dependent on the noise levels of the sensor. In tests conducted over $8 \mathrm{~s}$ the drift was found to be less than 0.1degrees at the end of the test.

\section{MODEL ACCURACY AND PERFORMANCE}

The initial preview model validation was performed using a validated ADAMS model of the vehicle. By using the ADAMS measurements as inputs to the preview model, the accuracy of 
the model was analysed. After the accuracy of the model was found to be sufficient, the model was tested on experimentally obtained data.

The VPM is coded in $\mathrm{C}++$ and implemented on an embedded computer, with a Linux operating system, that is mounted in the vehicle. The embedded computer is a Helios that consists of a PC-104 single board computer with a Vortex86DX CPU and integrated auto calibrating data acquisition as developed by Diamond Systems (Diamond Systems, 2013). The Vortex86DX CPU is a $800 \mathrm{MHz}$ single core processor with $256 \mathrm{MB}$ of on-board DRAM. It has 16 digital inputs, 16 digital outputs, 16 analogue inputs with 16-bit resolution and 4 analogue outputs with 12-bit resolution. The embedded system could successfully solve the VPM at a rate of $100 \mathrm{~Hz}$ which is adequate for most vehicle dynamics applications where the vehicle natural frequency is generally below $10 \mathrm{~Hz}$. The embedded system is rather slow in comparison to more modern computer systems. A more modern computer system may allow a more complex preview model can be used which may provide better results.

The Land Rover Defender 110 test vehicle is equipped with numerous sensors, listed in Table 1, to measure the vehicle states required as inputs to the VPM as well as to validate the VPM.

Table 1: Sensors on the vehicle

\begin{tabular}{|c|c|}
\hline Vehicle Parameter & Instrument \\
\hline Vehicle speed & Racelogic Velocity BOX 3 (VBOX3) Differential Global \\
& Positioning System (DGPS) \\
\hline Steering angle & Potentiometer \\
\hline Side-slip angle & Correvit S-HR \\
\hline Roll angle & 2x Acuity Lasers Displacement Sensors \\
\hline
\end{tabular}




\begin{tabular}{|c|c|}
\hline Roll rate & Solid state gyroscope (CRS03) \\
\hline Yaw rate & Solid state gyroscope (CRS03) \\
\hline CG lateral acceleration & Accelerometer (Crossbow 4g) \\
\hline CG vertical acceleration & Accelerometer (Crossbow 4g) \\
\hline GPS coordinates & Racelogic Velocity BOX 3 (VBOX3) Differential Global \\
& Positioning System (DGPS) \\
\hline
\end{tabular}

The speed of the vehicle was measured using a VBOX with a specified velocity accuracy of $0.1 \mathrm{~km} / \mathrm{h}$. This is indeed the case when the signal is logged on the internal memory of the VBOX, but when the speed was used as a real-time analog output from the VBOX to the VPM; it was found that a minimum speed of about $\mathrm{km} / \mathrm{h}$ could be measured. This is due to noise from the surroundings and the fact that using the DGPS base station data is not always obtainable when driving in the city. The steering angle was measured with a potentiometer installed on the kingpin of the right front wheel. The roll and yaw rate are measured using solid state gyroscopes. While the noise specifications of the gyroscopes are fairly low ( $1 \mathrm{mV}$ $r m s$ ) the noise induced by the vehicle vibrations itself is significant. The slip angle was measured using Correvit S-HR slip angle sensor. The sensor was mounted at the rear of the vehicle and the measurement moved to the CG using the yaw rate and distance to CG. In some tests the slip angle was also calculated by determining the lateral slip velocity by integrating the slip acceleration as:

$$
V_{y}=\int\left(\ddot{y}+V_{x} r\right) d t
$$

Two tests were conducted, the first is a ISO double lane change which represents a severe obstacle avoidance manoeuvre. The test was performed at various speeds and also at two 
suspension settings, stiff spring and damper and softs spring and damper. The second test was an increasing frequency sinusoidal manoeuvre which is a much slower manoeuvre than the DLC. The increasing frequency also gives an indication to the accuracy of the VPM as the vehicle motion becomes faster. This manoeuvre was also performed on two suspension settings.

The accuracy of the PVM was analysed by comparing the states obtained from the VPM to the actual vehicle response at the predicted time step. The preview time was adjusted from $50 \mathrm{~ms}$ to $500 \mathrm{~ms}$ in $50 \mathrm{~ms}$ increments. For comparison two metrics are used, the coefficient of determination $\left(R^{2}\right)$ and the Root Mean Square (RMS) error. The coefficient of determination is a number that indicates how well data fits a statistical model. The value can be considered to be normalised as the value ranges between 0 and 1 for no correlation and perfect correlation respectively. Due to this normalisation it is easy to compare the accuracy between different measurements which have different units. The RMS represents the standard deviation of the differences between the signals. The units are however the same as the measurements. If the accuracy of each parameter is to be assessed using the RMS each parameter would have a different threshold because the error is not normalised. The RMS error is provided for additional validation. The $R^{2}$ and RMS values were determined using filtered measured signals, using a zero phase shift filter, with a cut-off frequency of $20 \mathrm{~Hz}$ which is well below the expected $1 \mathrm{~Hz}$ body motion. Filtered signals were used to reduce the noise in the measurements as not to effect the determination $R^{2}$ and RMS negatively. The performance metrics were also computed only over the manoeuvre removing the steady state conditions at the beginning and the end of the manoeuvre. This was done to avoid bias in the performance metrics as at steady state the correlation is exact. 


\subsubsection{Double Lane Change}

The DLC is used as it represents a very severe manoeuvre containing sudden steering inputs. The manoeuvre is used to simulate an obstacle avoidance performed at high speeds. This manoeuvre would therefore adequately represent one of the most dynamics manoeuvres experienced by a vehicle. Figure 9 shows the estimation of the vehicle states performing a DLC with an entry speed of $70 \mathrm{~km} / \mathrm{h}$, the suspension is set to a hard spring and damper and the preview time is $0.25 \mathrm{~s}$. The VPM shows good ability to predict all states with the slip angle being the worst overall. The method where the slip angle is integrated shows better estimation of the slip angle than assuming it is initially zero. Even then the error at some of the peaks is larger than $100 \%$, however the measurement range is between \pm 1.5 degrees which is a small slip angle to measure accurately. The discrepancies are most likely due to the tyre model which was developed when the tyre was new and has deteriorated and aged at the time of testing.

Figure 10 shows the $R^{2}$ values for all states while performing a DLC at an entry speed of $70 \mathrm{~km} / \mathrm{h}$ with the spring and damper set to stiff. According to the figure the VPM methodology where the initial slip is assumed to be zero performs marginally worse, for almost all states, than the method where the slip-angle is integrated. The roll angle correlation is exceptionally well even at large preview times. If a $R^{2}$ value of 0.8 is taken as acceptable correlation then the VPM which integrates the slip angle can estimate the roll angle up to a preview of $0.35 \mathrm{~s}$ and with the zero slip method only up to $0.25 \mathrm{~s}$. The correlation of the slip angle is acceptable up to $0.1 \mathrm{~s}$ with the integrate slip angle method, with the other method and higher preview times being unacceptable. The correlation of the roll rate, yaw rate and lateral acceleration seems to be fairly poor as well. However, from the plots observed for the measured values, in Figure 9, it is observed that the noise levels are fairly high. The noise levels are most likely as a result of the vibrations of the vehicle itself, even with the filtering 
the measurements remain oscillatory. In Figure 11 the RMS error of the states are shown. In most cases the error value seems to be close to the noise band observed for these measurements. Therefore, the $R^{2}$ may not be sufficient to present the correlation of these measurements. From the RMS error it can also be observed that on average the integrated slip method performs better than the zero slip method. It can be noted that the estimation deteriorates with longer preview times, one reason for this is the assumption that the steer rate remains constant for the duration of the simulation. As noted this is only valid for short periods and not for longer periods hence one of the reasons for the poor estimation at longer preview times. Unfortunately it is not possible to predict the exact steer rate input to the vehicle in the future.

Figures 12 and 13 show the $R^{2}$ correlation and RMS error for the vehicle performing the DLC with an entry speed of $70 \mathrm{~km} / \mathrm{h}$ and the spring and damper set to soft. These plots again have very similar tendencies than the stiff suspension settings. The roll angle can be accurately predicted up to a preview time of $0.45 \mathrm{~s}$ and $0.5 \mathrm{~s}$ for the zero slip and integrated slip methods respectively. The reason why the roll angle estimation is better on the soft spring is that the assumption that the tyre deflection can be neglected is more valid on a soft spring than on a hard spring. On the hards spring the tyre deflection is a larger component of the overal vehicle roll angle as compared to the soft spring. Inclusion of the tyre deflection should improve the estimation at both spring settings.

\subsubsection{Increasing Frequency Sinusoidal Path}

The increasing frequency sinusoidal path is used to determine the accuracy of the VPM at different frequencies. The maximum frequency reached is only slightly lower than required for the DLC. Figure 14 shows the results of the VPM predicting the states for a preview time 
of $0.25 \mathrm{~s}$ while performing the sinusoidal path with the spring and damper set to soft. The figure shows good correlation between measured and predicted for all states except for the side-slip angle. The figure shows no noticeable difference between the two proposed methods. Figures 15 and 16 show the $R^{2}$ correlation and RMS error for the vehicle performing the increasing frequency sinusoidal path at a speed of $70 \mathrm{~km} / \mathrm{h}$ and the spring and damper set to soft. These plots show that the correlations of all states, except for the slip angle, are exceptional with $R^{2}$ above 0.8 even at very long preview times. Figures 17 and 18 show the $R^{2}$ correlation and RMS error for the same test, however performed with a stiff spring and damper setting. These figures also indicate good correlation of most states even at long preview times. The $R^{2}$ correlation for the roll rate is however significantly lower with the stiff suspension settting compared to the soft spring. This could be due to the noise in the measurement being larger compared to the actual excitation and the fact that the roll motion is very small due to the stiff suspension. The roll angle however still compares very well.

\subsubsection{Change in Tyre Parameters}

Since the tyre parameters are probably the most difficult to determine a test was conducted to dtermine the effect on a change of tyre parameters. The MF tyre coefficients were modified by increasing them by $20 \%$, this would effect the shape, cornering stiffness, friction coefficient as well as vertical load dependency of the tyre model. Figure 19 and 20 shows the $R^{2}$ correlation and RMS error performing a DLC with an entry speed of $70 \mathrm{~km} / \mathrm{h}$ and the spring and damper set to soft. In the figures it is clear theat the effect is to deteriorate the accuracy hwoever the effect is not as large as expected. At most the $R^{2}$ correlation of the slip angle is decreased by $15 \%$ and most other states the effect is close to and below a $5 \%$ decrease in accuracy. 
The results indicate that the model can be accurately used to estimate the roll angle for most situations. The yaw rate and lateral acceleration also compares favourably in most tests. The slip angle and roll rate however provide poor correlation in most tests. The poor slip angle correlation is most likely due to the model inadequately modelling this parameter. The poor correlation in the other measurements could partially be explained by the noise in the measurement which adversely affects the correlation. The VPM model was found to perform exceptionally well at lower frequency events while the higher frequency events show good correlations for only some states. It should be noted however that the correlation method used may also be inadequate. In most cases the VPM would be used as a precursory warning that the vehicle would roll or that the vehicle would lose control. In these cases it is more desirable that the model can predict the maximum roll rate and roll angle for roll over prevention and maximum yaw rate and lateral acceleration for loss of control. The model should therefore be validated for the intended purpose to determine whether it would be suitable to provide a preview estimate.

\section{CONCLUSIONS AND RECOMMENDATIONS}

An accurate VPM has been developed yielding satisfactory results. The results show that the roll angle of the vehicle is accurately predicted even at preview long preview times. The accuracy of the roll angle was also dependent on the suspensions settings. The roll angle can be predicted satisfactory up to $0.25 \mathrm{~s}$ with a stiff suspension, while with a softer suspension the preview can be performed up to $0.5 \mathrm{~s}$. Some of the other measurements contain large amounts of noise which adversely effects the correlations of these measurements. Even in the presence of all the sensor noise the model predicts most states satisfactory with the exception of the slip angle. The model shows promise to be used in many vehicle applications to give a precursory warning to loss of vehicle control. The model should however be validated for the 
specific task at hand as the correlation method used may not accurately represent the accuracy of the method for the intended task. If the steer rate profile input to the vehicle can be determined exactly then better estimation of the vehicle states can be performed at longer preview times, this can perhaps be done by using statistical data, knowledge of the path or using heuristics.

The predictions were made on the vehicle in real-time using little computing power and at a sampling frequency of $100 \mathrm{~Hz}$.

The VPM can also be tuned to provide the required preview for specific applications. The VPM should next be used to predict the input states to different control strategies. The VPM can then be validated on its ability to improve the handling of the vehicle and the safety of the occupants since it can provide early warning detection and reduce the delay in the control algorithm.

Implementation of the VPM is expected to significantly improve the performance of many vehicle dynamics control systems. 


\section{References}

[1] Governer's Office of Consumer Affairs. (2013) SUV rollover accident and death statistics, [online]

https://www.google.co.za/\#q=Governer's+office+of+cosumer+affairs+SUV+rollover+ accident+and+death+statistics, (Accessed 5 September 2013).

[2] Strashny A. (2007) 'U.S. Department of Transportation National Highway Traffic Safety Administration, An Analysis of Motor Vehicle Rollover Crashes and Injury Outcomes'

[3] Road Traffic Management Corporation. (2013) Road Traffic Report for the Calendar Year, [online] http://www.arrivealive.co.za/documents/Year_2009__Road_Traffic_Report_-_V2.pdf, (Accessed 5 September 5 2013).

[4] Australian College of Road Safety. (2013) Rollover propensity, [online] http://acrs.org.au/about-us/policies/safe-vehicles/rollover-propensity/. (Accessed 5 September 5 2013).

[5] Cronje, P.H. and Els, P.S. (2009) 'Improving off-road vehicle handling using an active anti-roll bar', Journal of Terramechanics, Vol. 47 No. 3, pp. 179-189

[6] van der Westhuizen, S.F. and Els, P.S. (2013) 'Slow active suspension control for rollover prevention', Journal of Terramechanics, Vol. 50, No. 1, pp. 29-36.

[7] Els, P.S. (2006) The ride comfort vs. handling compromise for off-road vehicles, Unpublished PhD thesis, Department of Mechanical and Aeronautical Engineering, Faculty of Engineering, University of Pretoria.

[8] Rahman, M. and Rideout, G. (2012) 'Using the lead vehicle as preview sensor in convoy vehicle active suspension control' Vehicle Systems Dynamics: International Journal of Vehicle Mechanics and Mobility, Vol. 50, No. 12, pp. 1923-1948. 
[9] Feng, J., Bei, S., Yuan, C. and Zhang, L. (2009) 'Research on Wheelbase Preview Control for Vehicle Semi-Active Suspension Based on Neural Networks' Third International Symposium on Intelligent Information Teachnology Application.

[10] Yim, S. (2011) 'Design of Preview Controller for Vehicle Rollover Prevention', IEEE Transactions on Vehicular Technology, Vol. 60, No. 9, pp. 4217-4226

[11] Chen, B. and Peng, H. (1999) 'A Real-time Rollover Threat Index for Sport Utility Vehicles' Proceeding of the American Control Conference, June, 1999, San Diego, California

[12] Licea, M.R. and Cervantes, I. (2012) 'On the Predictive Rollover Detection in Wheeled Vehicles', 38th Annual Conference on IEEE Industrial Electronics Society, October, 2012, Montreal, QC.

[13] Sanchez, E.N., Ricalde, L.J., Langari, R. and Shahmirzadi, D. (2004) 'Rollover Prediction and Control in Heavy Vehicles via Recurrent Neural Networks' $43^{\text {rd }}$ IEEE Conference on Decision Control, December, 2004, Atlantis, Bahamas.

[14] Pacejka, H.B., Bakker, E. and Lidner, L. (1989) 'A New Tire Model with an Application in Vehicle Dynamics Studies', SAE paper 890087.

[15] Abe, M. (2009) Vehicle Handling Dynamics, Butterworth-Heinemann.

[16] Uys, P.E., Els, P.S., Thoresson, M.J., Voight, K.G. and Combrinck, W.C. (2006) 'Experimental Determination of Moments of Inertia for an Off-Road Vehicle with a Regular Engineering Laboratory', International Journal of Mechanical Education. Vol. 34, No. 4, pp. 291-314.

[17] Thoresson, M.J. (2007) Efficient Gradient-Based Optimisation of Suspension Characteristics for an Off-Road Vehicle. Unpublished PhD thesis, University of Pretoria, Pretoria, South Africa, [online] http://upetd.up.ac.za/thesis/available/etd$\underline{08042008-093103 / .}$ 
Autocalibrating Data Acquisition, [online]

http://www.diamondsystems.com/products/helios, (Accessed 5 October, 2013).

\section{Nomenclature}

\begin{tabular}{|c|c|c|c|}
\hline$d_{f}$ & Front Track Width & $\dot{r}$ & Yaw acceleration $\left[\mathrm{rad} / \mathrm{s}^{2}\right]$ \\
\hline$d_{r}$ & Rear Track Width & $R^{2}$ & Coefficient of determination \\
\hline$F_{l f}$ & Left front lateral tyre force $[N]$ & $t_{s}$ & Distance between suspension struts $[\mathrm{m}]$ \\
\hline$F_{l r}$ & Left rear lateral tyre force $[N]$ & $V$ & Velocity $[\mathrm{km} / \mathrm{h}]$ \\
\hline$F_{r f}$ & Right front lateral tyre force $[N]$ & $\ddot{y}$ & Lateral Acceleration $\left[\mathrm{m} / \mathrm{s}^{2}\right]$ \\
\hline$F_{r r}$ & Right rear lateral tyre force $[N]$ & $z_{S l}$ & $\begin{array}{l}\text { Suspension displacement of left struts } \\
{[\mathrm{m}]}\end{array}$ \\
\hline$F_{S l}$ & Sum of suspension forces on the left $[N]$ & $z_{S r}$ & $\begin{array}{l}\text { Suspension displacement of right struts } \\
{[\mathrm{m}]}\end{array}$ \\
\hline$F_{S r}$ & $\begin{array}{l}\text { Sum of suspension forces on the right } \\
{[N]}\end{array}$ & $\dot{z}_{S l}$ & Suspension velocity of left struts $[\mathrm{m} / \mathrm{s}]$ \\
\hline$F_{y}$ & Lateral force $[N]$ & $\dot{z}_{S r}$ & Suspension velocity of right struts $[\mathrm{m} / \mathrm{s}]$ \\
\hline$F_{y l}$ & $\begin{array}{l}\text { Sum of lateral forces of tyres on the left } \\
{[N]}\end{array}$ & $\beta$ & Vehicle side-slip angle $[\mathrm{rad}]$ \\
\hline$F_{y r}$ & $\begin{array}{l}\text { Sum of lateral forces of tyres on the right } \\
{[N]}\end{array}$ & $\dot{\beta}$ & Vehicle side-slip rate $[\mathrm{rad} / \mathrm{s}]$ \\
\hline$h_{r}$ & $\begin{array}{l}\text { Height of sprung mass from the roll } \\
\text { centre (roll arm) }[\mathrm{m}]\end{array}$ & $\beta_{l f}$ & Left front tyre side-slip angle $[\mathrm{rad}]$ \\
\hline$I_{x}$ & Roll mass moment of inertia $\left[\mathrm{kgm}^{2}\right]$ & $\beta_{r f}$ & Right front tyre side-slip angle $[\mathrm{rad}]$ \\
\hline$I_{z}$ & Yaw mass moment of inertia $\left[\mathrm{kgm}^{2}\right]$ & $\beta_{r r}$ & Rear rear tyre side-slip angle $[\mathrm{rad}]$ \\
\hline$l_{f}$ & $\begin{array}{l}\text { Distance from front axle to centre of } \\
\text { gravity }[\mathrm{m}]\end{array}$ & $\beta_{l r}$ & Left rear tyre side-slip angle $[\mathrm{rad}]$ \\
\hline$l_{r}$ & $\begin{array}{l}\text { Distance from rear axle to centre of } \\
\text { gravity }[\mathrm{m}]\end{array}$ & $\delta$ & Steering angle $[\mathrm{rad}]$ \\
\hline$n_{b}$ & Mass of vehicle body $[\mathrm{kg}]$ & $\dot{\delta}$ & Steering rate $[\mathrm{rad} / \mathrm{s}]$ \\
\hline
\end{tabular}


$m \quad$ Mass of entire vehicle $[\mathrm{kg}]$

$M_{x} \quad$ Moment about longitudinal axis $[\mathrm{Nm}]$

$r \quad$ Yaw rate $[\mathrm{rad} / \mathrm{s}]$ $\tau \quad$ Preview time $[s]$

$\varphi \quad$ Roll angle $[\mathrm{rad}]$

$\ddot{\varphi} \quad$ Roll acceleration $\left[\mathrm{rad} / \mathrm{s}^{2}\right]$

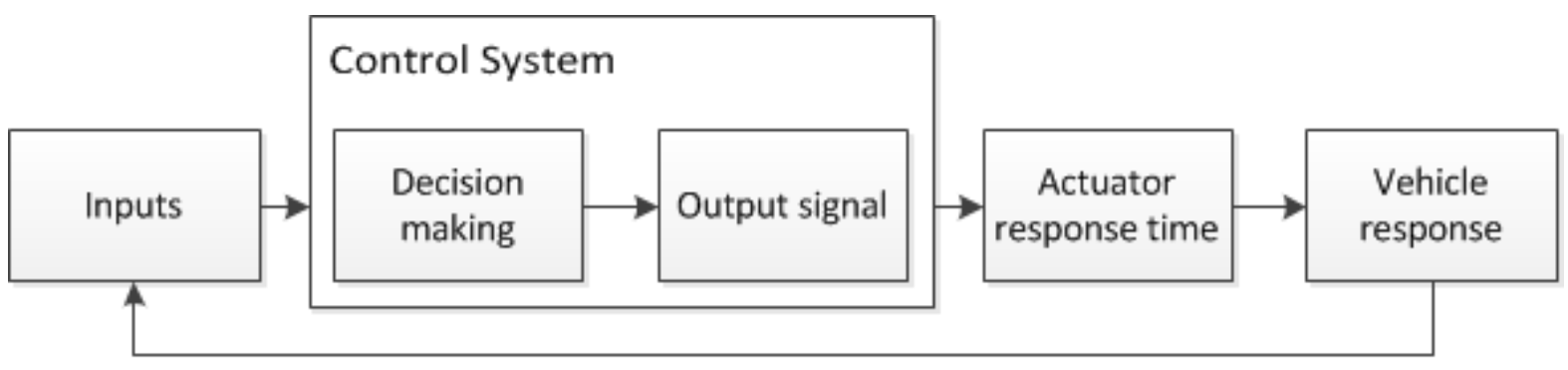

Figure 1: Control system delay 


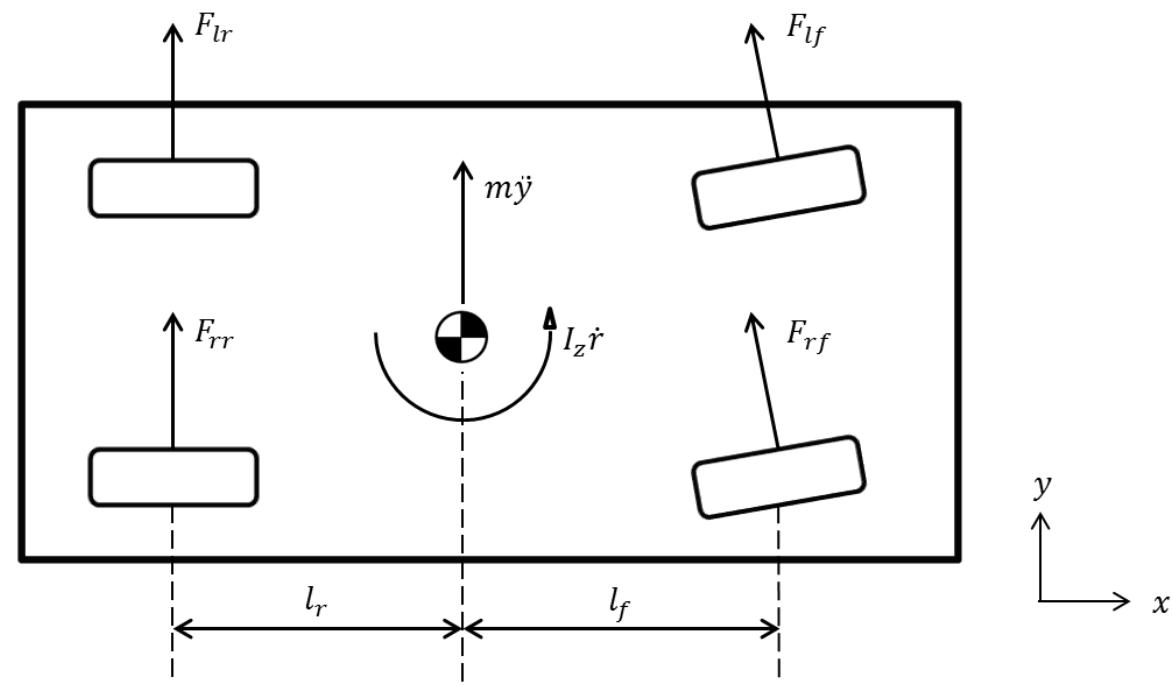

Figure 2: Top view for the vehicle lateral and yaw motion 


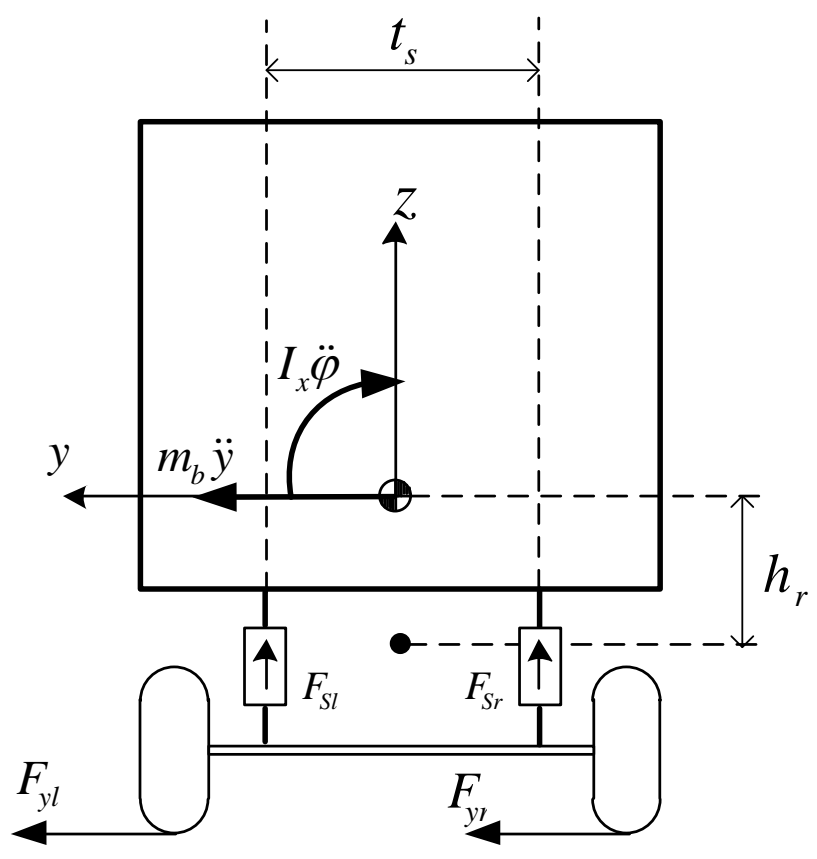

Figure 3: Rear view for the vehicle roll motion 


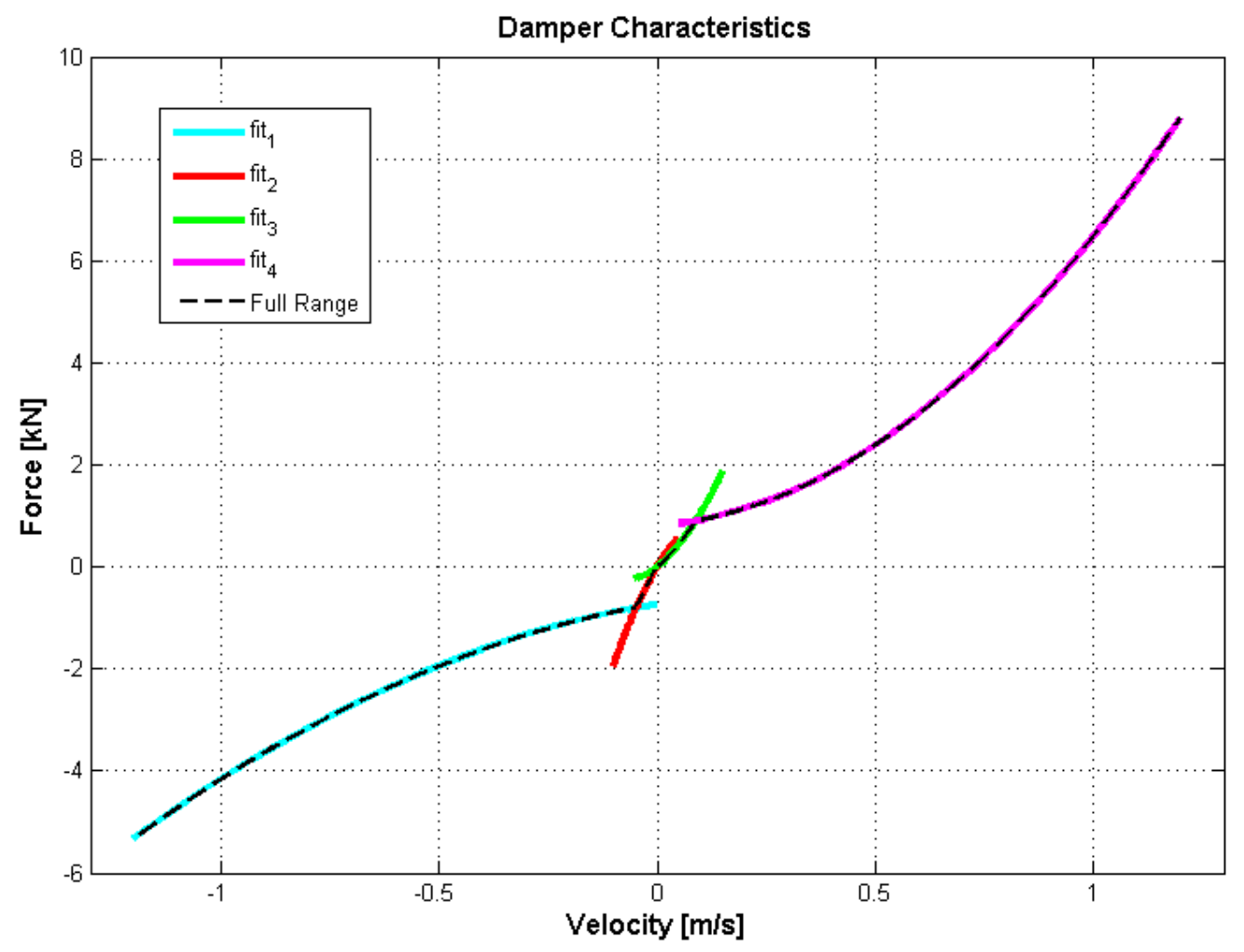

Figure 4: Damper characteristics 


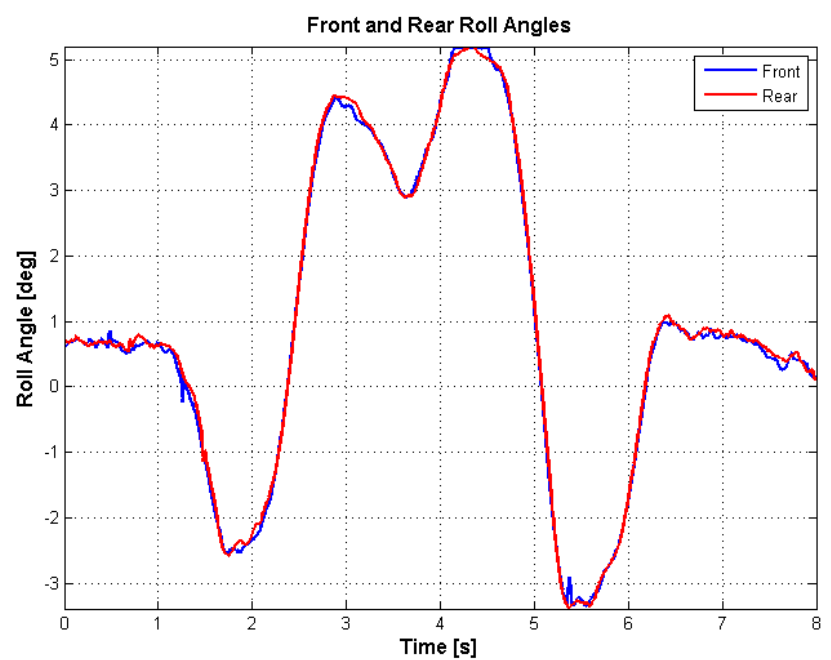

Figure 5: Roll angle measured at the front and rear of the vehicle 

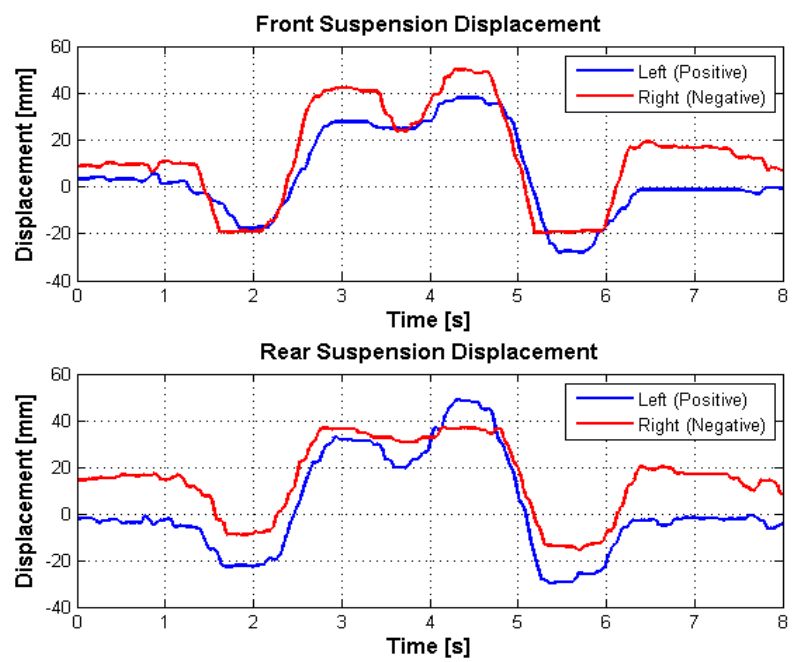

Figure 6: Left and right suspension displacements 

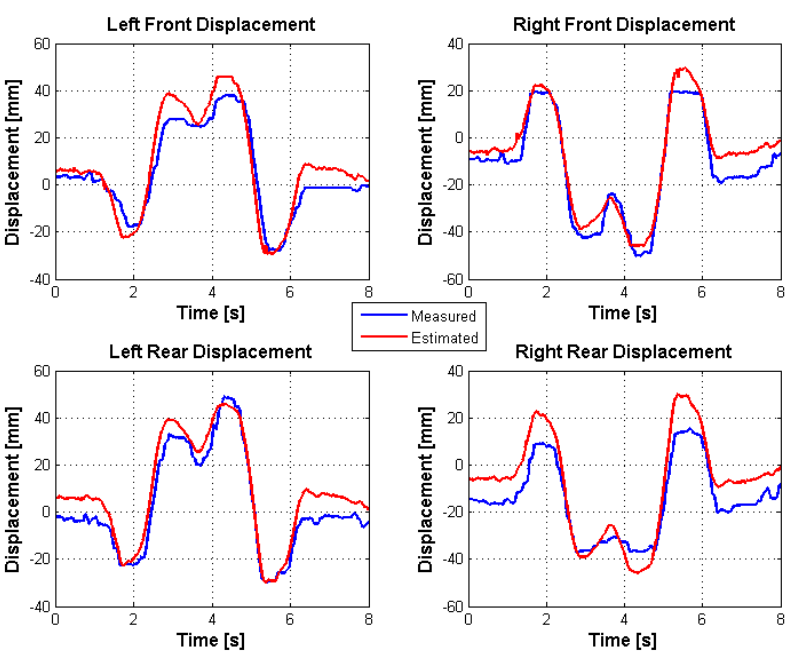

Figure 7: Measured suspension displacement vs. estimated suspension displacement 


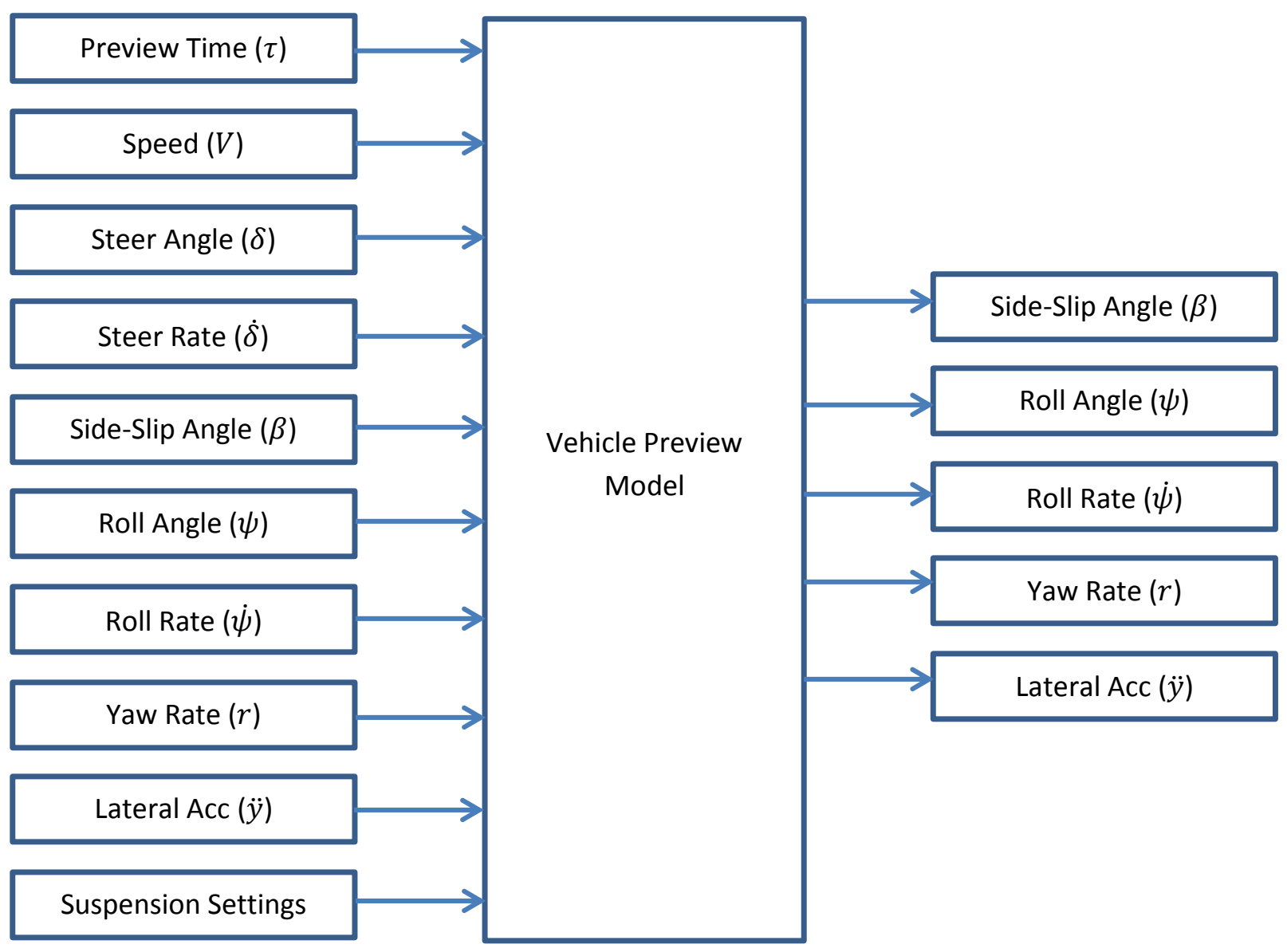

Figure 8: Vehicle Preview Model schematic 

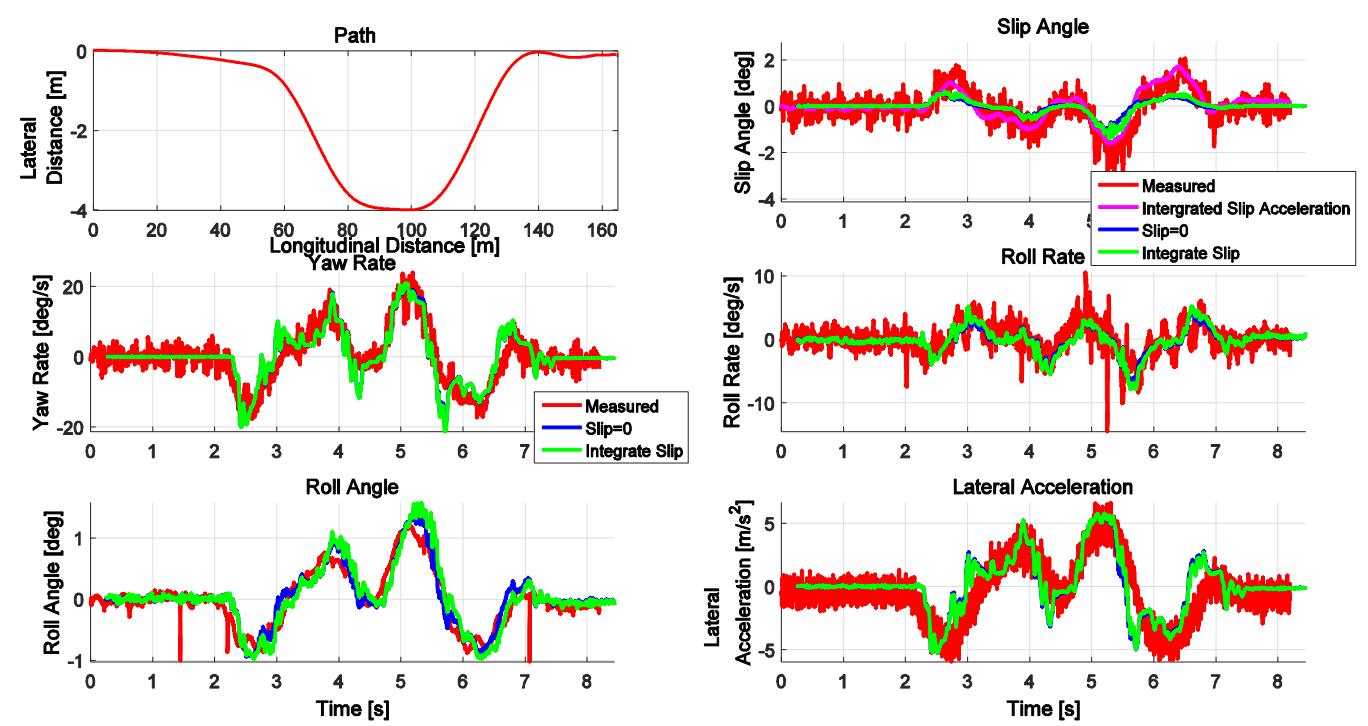

Figure 9: DLC at $70 \mathrm{~km} / \mathrm{h}$, suspension with stiff spring and damper and preview time of $0.25 \mathrm{~s}$ 

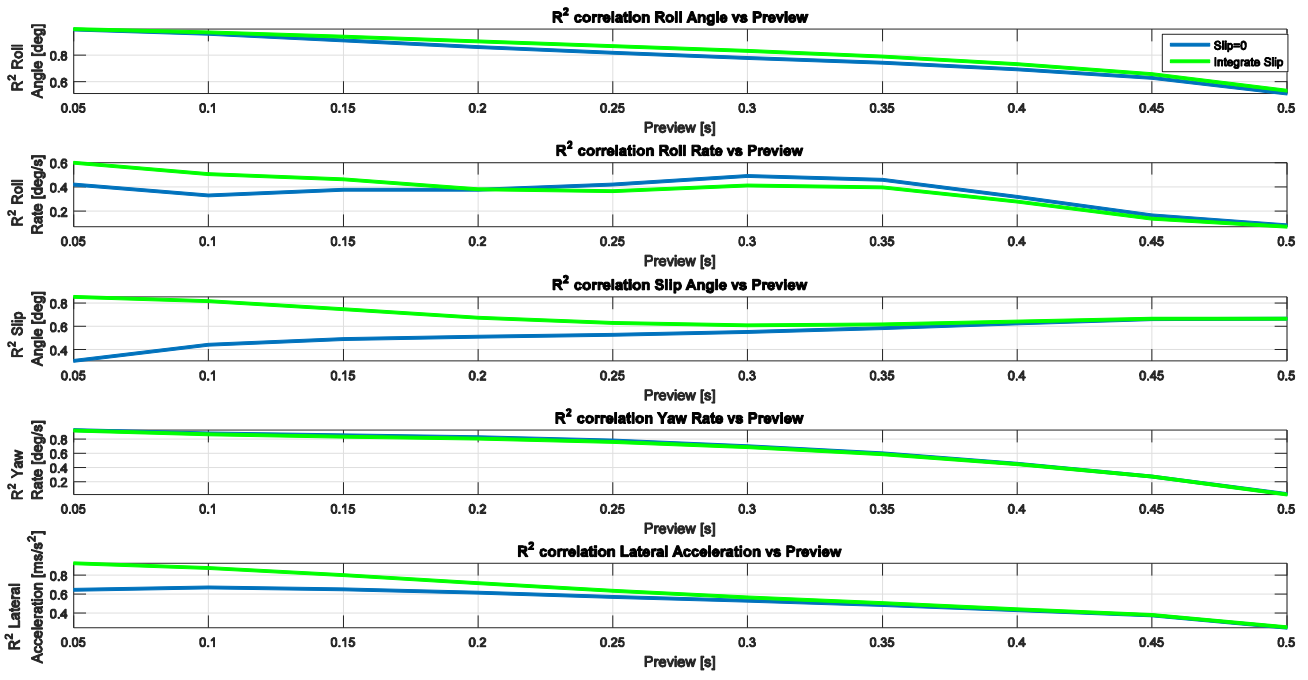

Figure 10: $R^{2}$ correlation performing DLC at $70 \mathrm{~km} / \mathrm{h}$, suspension with stiff spring and damper at various preview times 

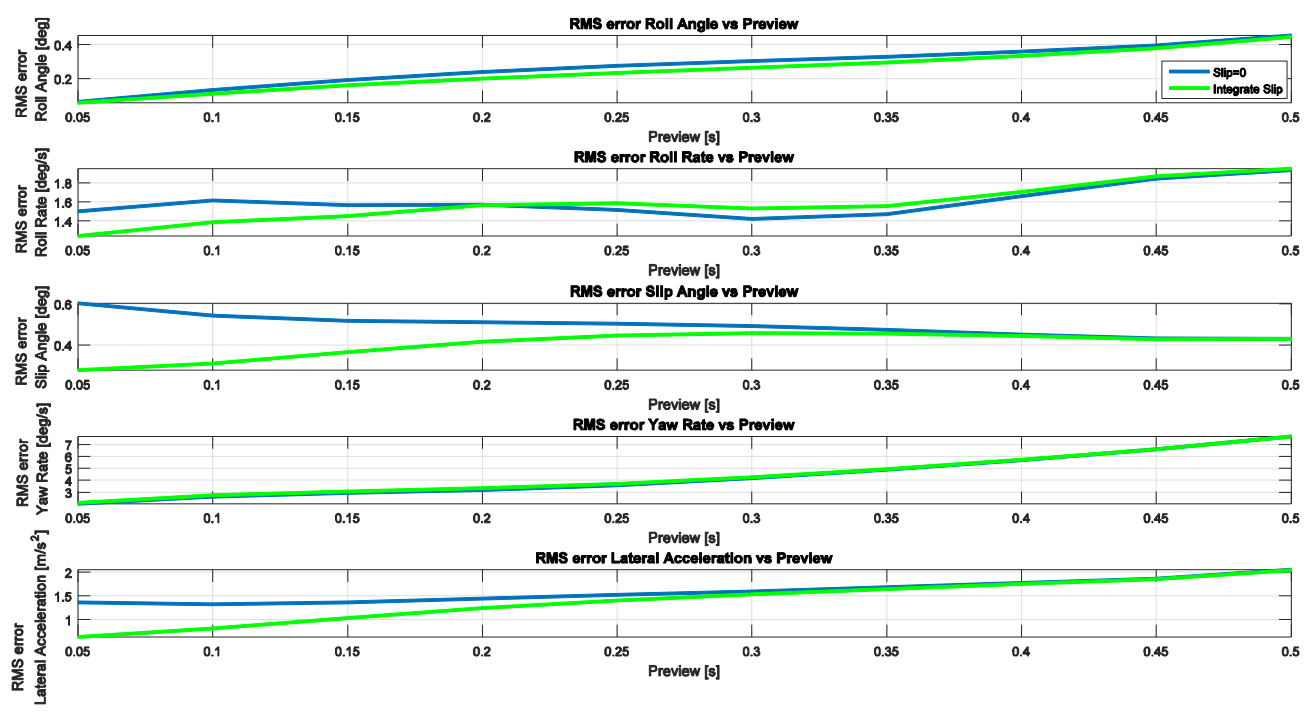

Figure 11: RMS error performing DLC at $70 \mathrm{~km} / \mathrm{h}$, suspension with stiff spring and damper at various preview times 

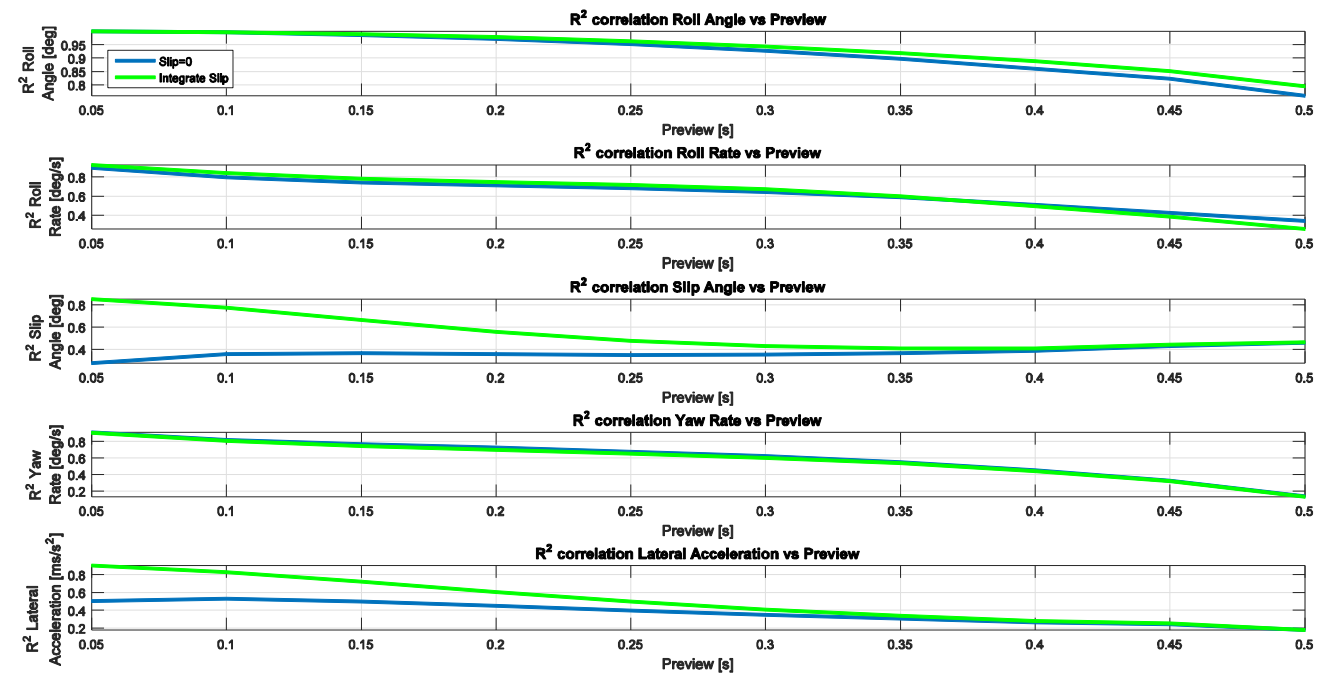

Figure 12: $R^{2}$ correlation performing DLC at $70 \mathrm{~km} / \mathrm{h}$, suspension with soft spring and damper at various preview times. 

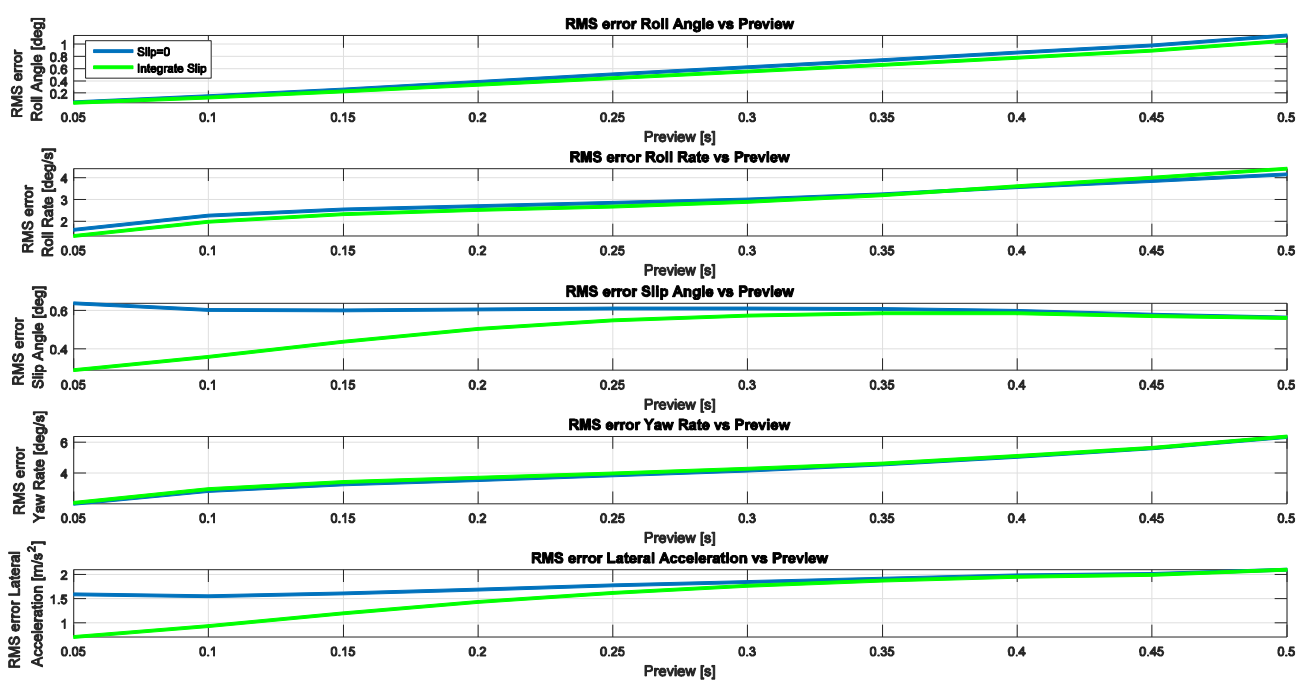

Figure 13: RMS error performing DLC at $70 \mathrm{~km} / \mathrm{h}$, suspension with soft spring and damper at various preview times 

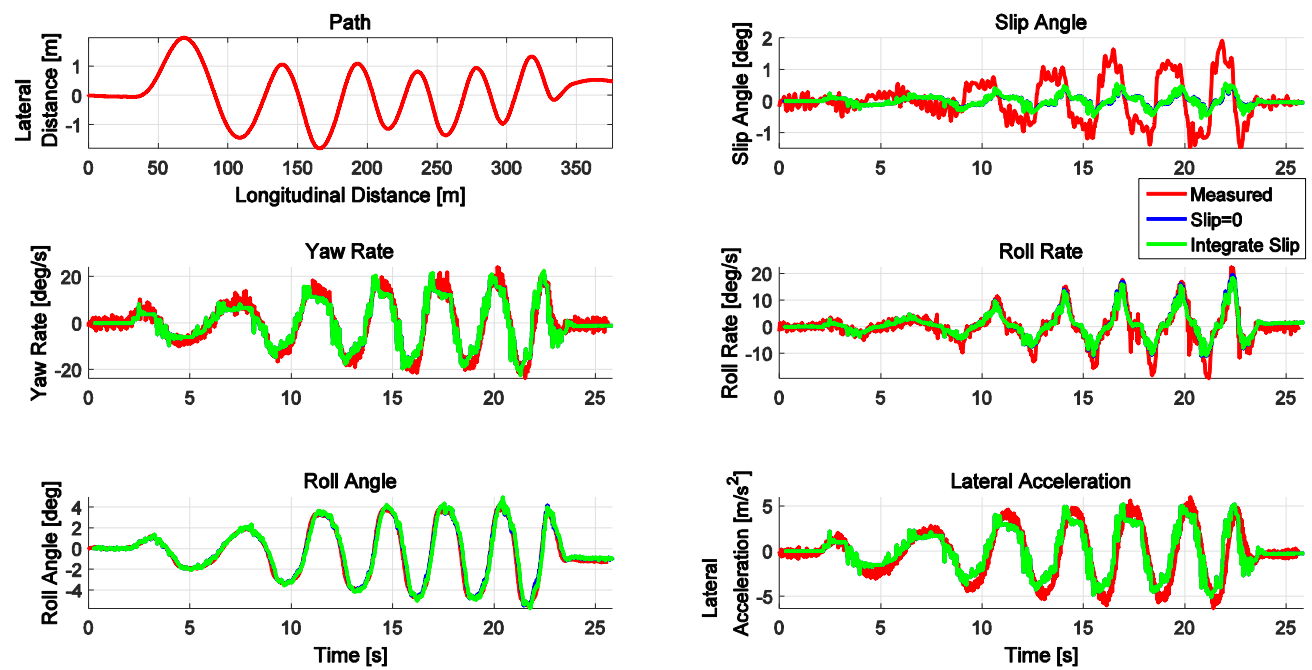

Figure 14: Increasing sinusoidal path at $50 \mathrm{~km} / \mathrm{h}$, suspension with soft spring and damper and preview time of $0.25 \mathrm{~s}$ 

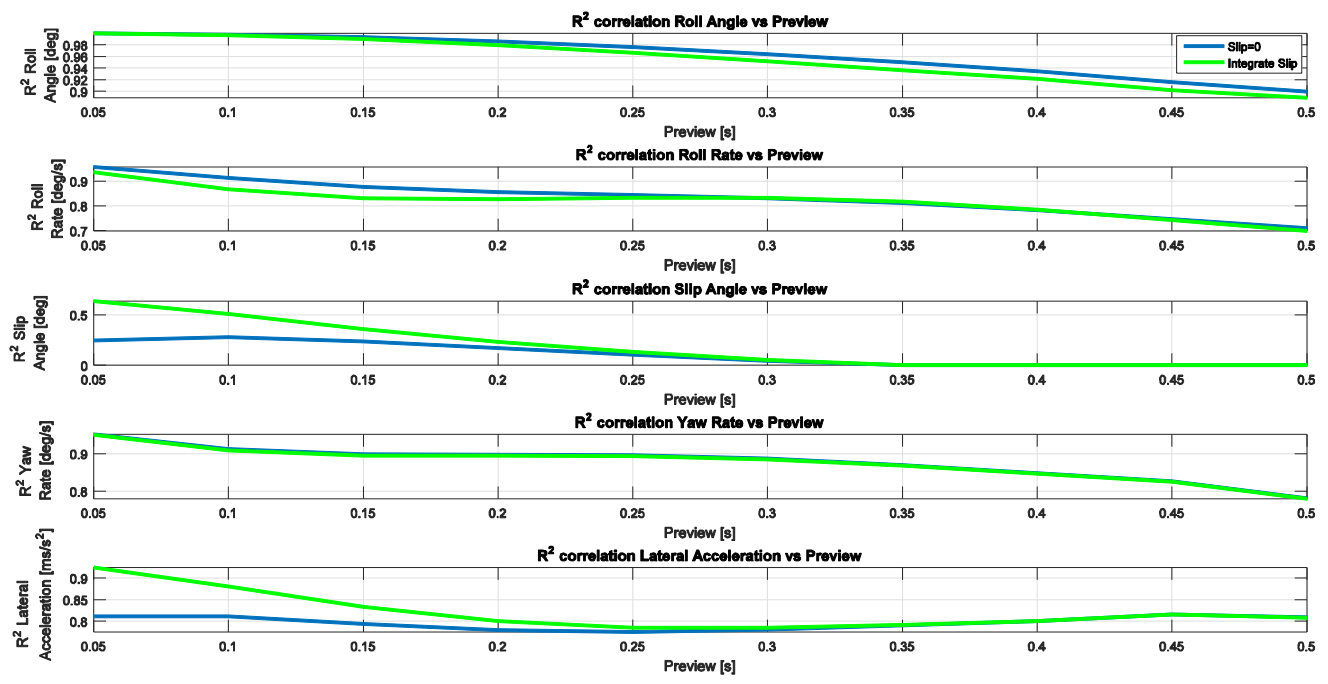

Figure 15: $R^{2}$ correlation while performing increasing frequency sinusoidal path at $50 \mathrm{~km} / \mathrm{h}$, suspension with soft spring and damper at various preview times 

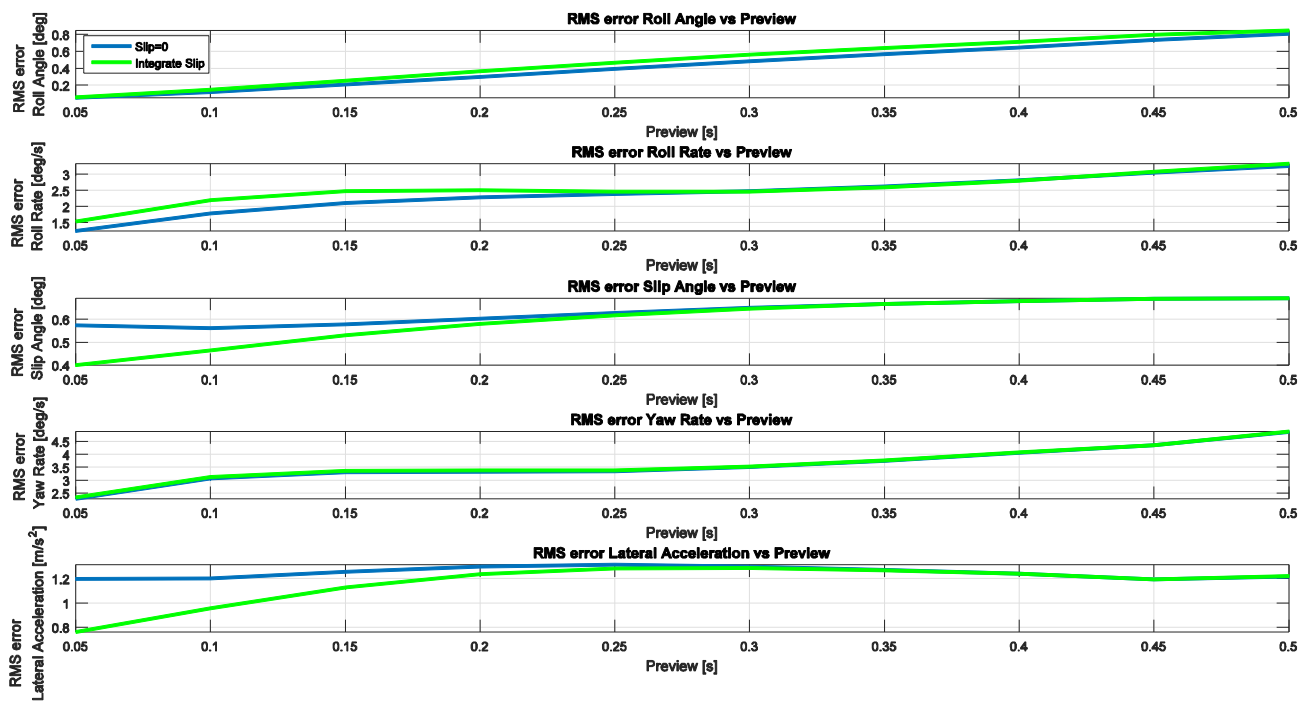

Figure 16: RMS error while performing increasing frequency sinusoidal path at $50 \mathrm{~km} / \mathrm{h}$, with soft spring and damper at various preview times 

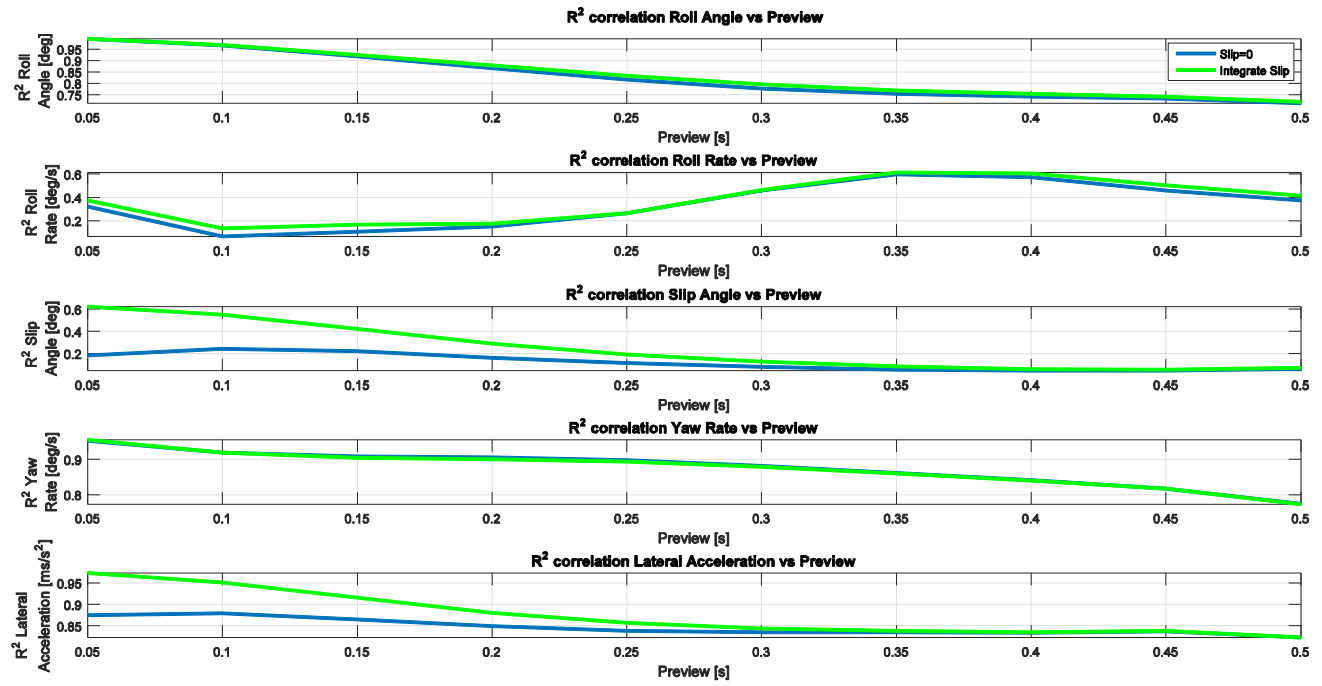

Figure 17: $R^{2}$ correlation while performing increasing frequency sinusoidal path at $50 \mathrm{~km} / \mathrm{h}$, with hard spring and damper 

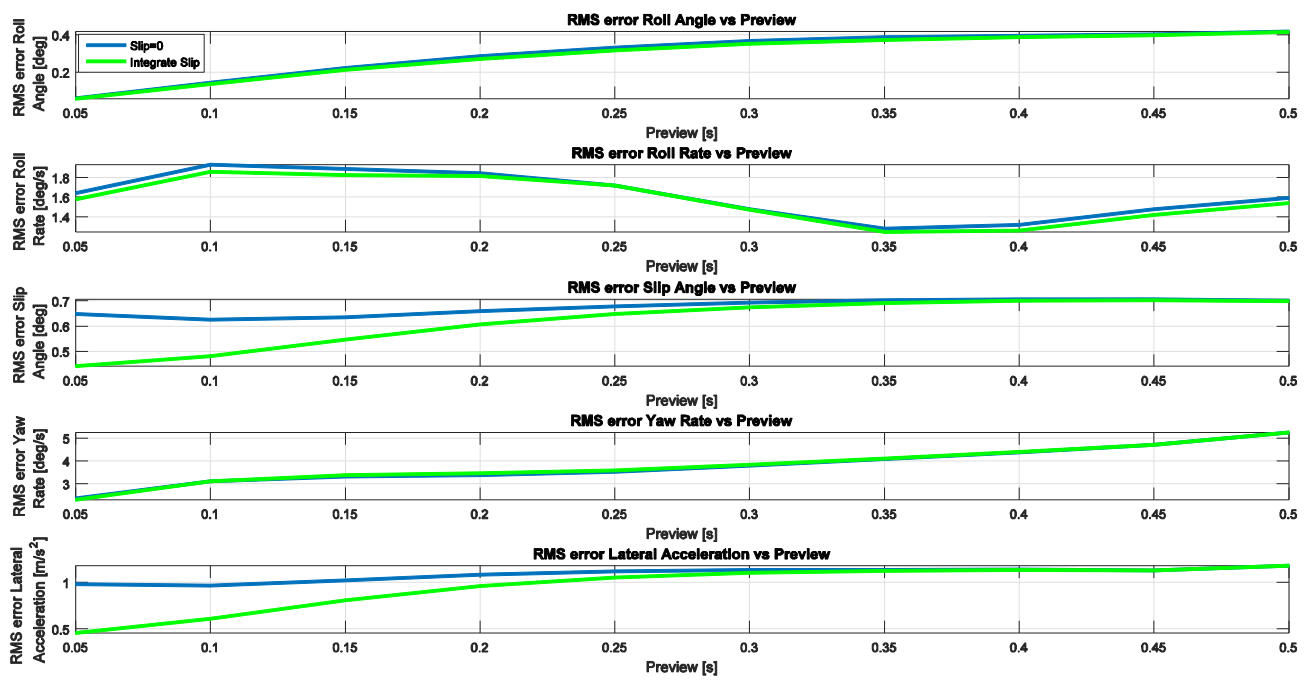

Figure 18: RMS error while performing increasing frequency sinusoidal path at $50 \mathrm{~km} / \mathrm{h}$, with hard spring and damper 

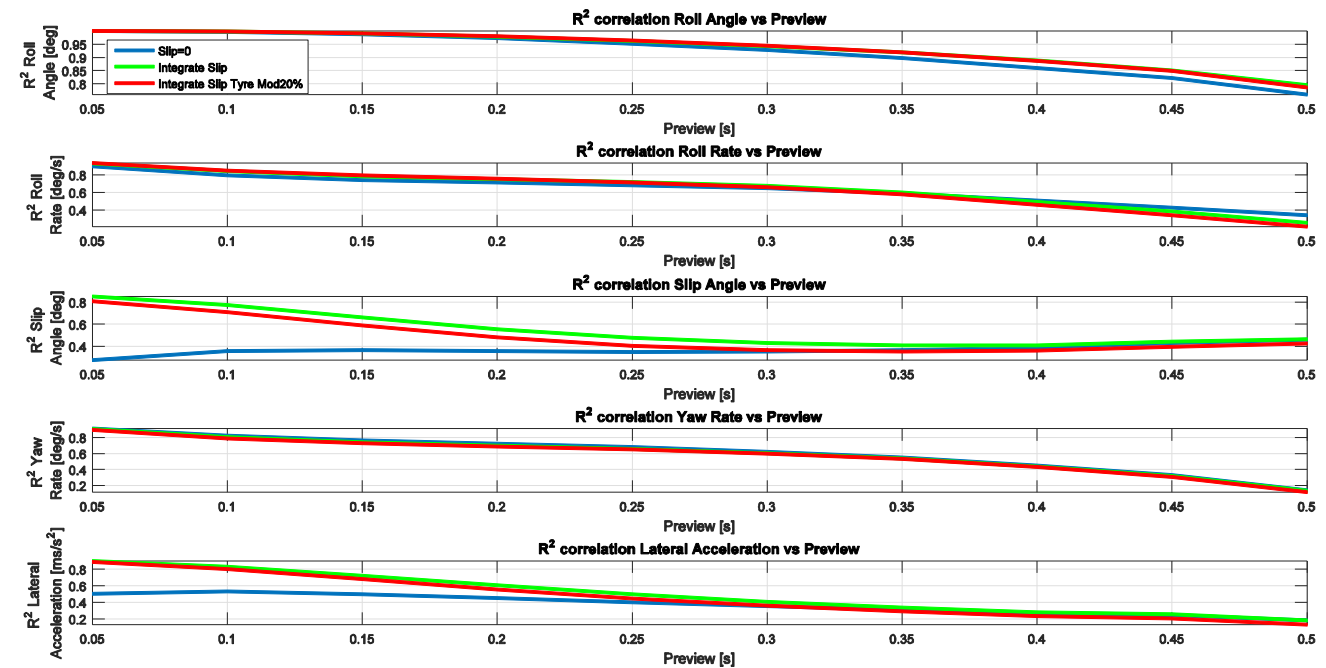

Figure 19: $R^{2}$ correlation while a DLC with entry speed of $70 \mathrm{~km} / \mathrm{h}$, with soft spring and damper showing effect of changing tyre parameters by $20 \%$ 

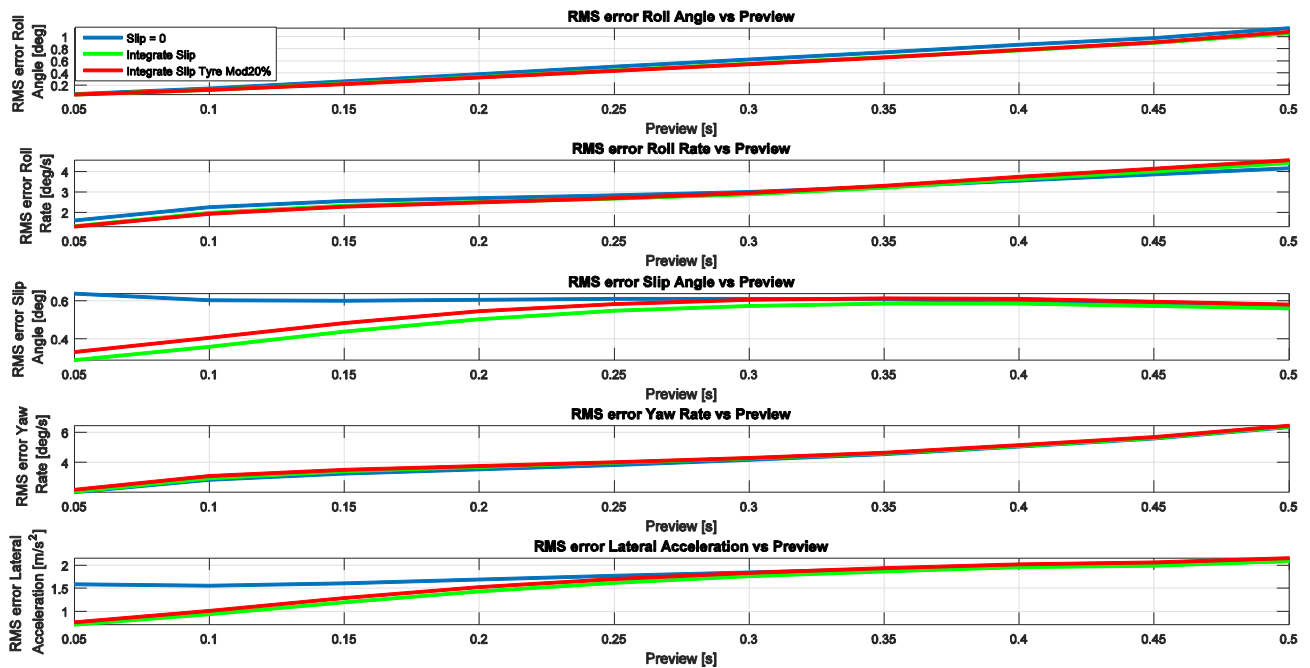

Figure 20: RMS error while a DLC with entry speed of $70 \mathrm{~km} / \mathrm{h}$, with soft spring and damper showing effect of changing tyre parameters by $20 \%$ 